\title{
ВЕНЧУРИНГ ТЕХНОЛОГИЙ В США: РАЗВИТИЕ РЫНКА И ПРАКТИКА СОВРЕМЕННЫХ СТАРТАПОВ
}

\author{
(c) 2021 Воинов А.И. \\ Московский государственный институт международных отношений (МГИМО), \\ Международный институт энергетической политики и управления инновациями, Россия, Москва \\ E-mail:vo_innov@mail.ru \\ (C) 2021 Торкановский Е.П. \\ Институт экономики Российской Академии Наук, Россия, Москва \\ E-mail: torkanovsky@gmail.com \\ (c) 2021 Шакирова А.А. \\ Российская государственная академия интеллектуальной собственности (РГАИС), Россия, Москва \\ E-mail: tonys132435@gmail.com \\ Американская система венчурного финансирования более полувека считается своеобразным \\ организационно-структурным эталоном для института рискового капитала по всему миру, чему \\ посвящено значительное число публикаций специалистов. Тем не менее, остаются актуальными и \\ другие специфические факторы развития национального рынка венчуров, влияющие на передовые \\ технологические достижения Соединенных Штатов.
}

Ключевые слова: институциональная инфраструктура, архитектура рынка, патентование

\section{Введение}

Венчурное финансирование относительно молодое направление бизнеса, которое берет свое начало в США первой половины XX века. Его генезис обусловлен спадами в национальной экономике, вызванными Великой Депрессией, а также участием страны в ряде продолжительных войн. Эти обстоятельства послужили предпринимателям мотивом для поиска новых путей стабилизации экономической ситуации. В 1930-е гг. в стране был сосредоточен излишек свободного капитала, и именно тогда началась активная поддержка, связанная с высоким уровнем риска при реализации, малых наукоемких предприятий. Инвесторы искали выгодный объект для извлечения наибольшей прибыли, а финансируемые ими предприятия предлагали технологичный товар для интенсификации промышленного сектора. Частные инвесторы высоко оценивали потенциал таких предприятий, всё чаще вкладываясь в них. Постепенно от частного инвестирования бизнес-ангелов венчурное финансирование качественно трансформирова- лось в официальный институт.

Первый фонд прямых инвестиций «American Research and Development» был учрежден в 1946 г., и уже в 1950-е гг. венчурный капитал оформился в статусе альтернативного источника финансирования высокотехнологичного бизнеса. Такие стремительные темпы обязали федеральные власти США законодательно закрепить основы венчурной деятельности, что послужило триггером к выстраиванию целостной институциональной инфраструктуры, регулирующей сферу венчурного финансирования.

\section{Рынок венчуров}

Всё новое во многом требует тщательного осмысления и профессионального подхода. Однако без допущенных ошибок невозможно создать эффективную систему госрегулирования. На пути ее формирования венчурная индустрия пережила несколько спадов из-за достаточно быстрой смены технологических драйверов*, выхода на рынок неопытных инвесторов, не обладающих необходимой финансовой грамотностью, переизбытка денежной массы в связи с

\footnotetext{
* Рыбин М.В., Воинов А.И. Теоретические аспекты и развитие методов управления инновациями // Экономические науки, 2020.- № 4.- С. 37-43.
} 
привлечением капиталов пенсионных фондов, а также по причине неточностей законодательства.

Но со стороны правительства США оперативно был предпринят ряд стратегически продуманных действий, стимулирующих и поддерживающих активность национального рынка рискового капитала: снижение ставки налога на прибыль для «стартапов», закон о малом бизнесе (согласно которому государственные средства направлялись в квалифицированные инвестиционные компании малого бизнеса (SBIC)), принятие закона о безопасности пенсионных отчислений (поскольку пенсионные фонды также имели право принимать участие в венчурном финансировании (до 5\% от капитала))*.

Благодаря комплексным программам поддержки со стороны государства инновационного потенциала малых наукоемких предприятий за указанный промежуток времени (Рис. 1) США прошли несколько «пиков» по объемам инвестируемого венчурного капитала и его рентабельности [13] [14], не покидая лидерскую позицию с 1960-х гг. Например, «в рамках межведомственной Программы инновационных исследований малого бизнеса (Small Business Innovation
Research) на конкурсной основе предоставляются гранты малым научным предприятиям для их целевого участия в программах исследований и разработок 11-ти федеральных ведомств. Параллельно реализуется Программа технологических трансферных исследований малого бизнеса (Small Business Technology Transfer Research)»*** и ряд других долгосрочных ГЧП-программ федерального значения ${ }^{* * *}$. Обзор экспертов британского издания «The Economist», подготовленный в 2018 г., показал, что Соединенные Штаты фактически на 15 лет опережают своего ближайшего технологического конкурента - Китай ${ }^{* * * * ;}$ в частности за счет нарастающих темпов в венчуринге технологий VI укладаж*****. В ближайшие 10 лет Пекин обещает превратиться в полноценного конкурента «Кремниевой долины». Китайские стартапы проходят жизненный цикл за 3-5 лет, в американских штатах на это же уходит 5-8 лет. Время запуска нового венчурного проекта от идеи до производства со всей его ресурсной базой в Шеньчжене - 3-6 месяцев. Однако международные статистические базы фиксируют следующее положение США на мировом рынке инноваций в 2019-м и 2020-м гг. (Рис. 2, 3).

* Плотников Д.А. Венчурный бизнес: опыт США // Инновационная деятельность, 2009. - № 2 (7). - С. 62-68.URL: https://elibrary.ru/item.asp?id=12858260 (дата обращения 18.12.2019).

** Воинов А. И. Особенности научно-технологической политики США // Финансовый бизнес, 2015.- № 3.- С. $57-61$.

**** Варнавский В.Г., Зельднер А.Г., Мочальников В.Н., Сильвестров С. Н. Основы государственно-частного партнерства (теория, методология, практика).- М.: Анкил, 2015.

***** Воинов А. И. Национальная научно-технологическая политика Китая // Биржа интеллектуальной собственности, 2015.- № 3.- С. 40, 41.

****** Современные международные экономические отношения в эпоху постбиполярности: монография / Т.М. Исаченко, Л.С.Ревенко, И.Н.Платонова [и др.]; под общей редакцией Т. М. Исаченко.- М.: МГИМО-Университет, 2020.- С. 536-545.

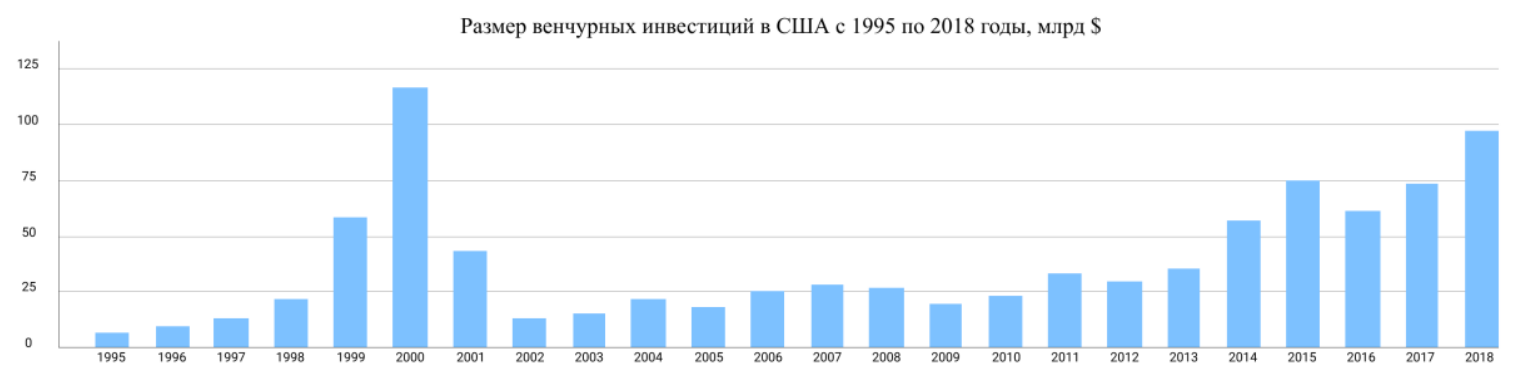

Puc. 1. Источник: https://www.statista.com/statistics/277501/venture-capital-amount-invested-in-theunited-states-since-1995/ (дата обращения 12.10.2020). 


\begin{tabular}{|c|c|c|c|c|}
\hline \multirow[b]{2}{*}{2020} & \multicolumn{4}{|c|}{$\begin{array}{c}\text { Рейтинг инновационных экономик мира } \\
\text { по итогам } 2020 \text { года }\end{array}$} \\
\hline & 2019 & YoY & & Total \\
\hline Rank & Rank & Change & Economy & Score \\
\hline 1 & 2 & +1 & Germany & 88.21 \\
\hline 2 & 1 & -1 & S. Korea & 88.16 \\
\hline 3 & 6 & +3 & Singapore & 87.01 \\
\hline 4 & 4 & 0 & Switzerland & 85.67 \\
\hline 5 & 7 & +2 & Sweden & 85.50 \\
\hline 6 & 5 & -1 & Israel & 85.03 \\
\hline 7 & 3 & -4 & Finland & 84.00 \\
\hline 8 & 11 & +3 & Denmark & 83.22 \\
\hline 9 & 8 & -1 & U.S. & 83.17 \\
\hline 10 & 10 & 0 & France & 82.75 \\
\hline 11 & 12 & +1 & Austria & 82.40 \\
\hline 12 & 9 & -3 & Japan & 82.31 \\
\hline 13 & 15 & +2 & Netherlands & 81.28 \\
\hline 14 & 13 & -1 & Belgium & 79.93 \\
\hline 15 & 16 & +1 & China & 78.80 \\
\hline 16 & 14 & -2 & Ireland & 78.65 \\
\hline 17 & 17 & 0 & Norway & 76.93 \\
\hline 18 & 18 & 0 & U.K. & 76.03 \\
\hline 19 & 21 & +2 & Italy & 75.76 \\
\hline 20 & 19 & -1 & Australia & 74.13 \\
\hline 21 & 31 & +10 & Slovenia & 73.93 \\
\hline 22 & 20 & -2 & Canada & 73.11 \\
\hline
\end{tabular}

Puc. 2. Источник: Global Innovation Index 2020 https://www.globalinnovationindex.org/gii-2019-report\# (дата обращения 13.04.2021).

Объем рынков венчурного капитала: Северная Америка, Европа и Азия, млрд \$

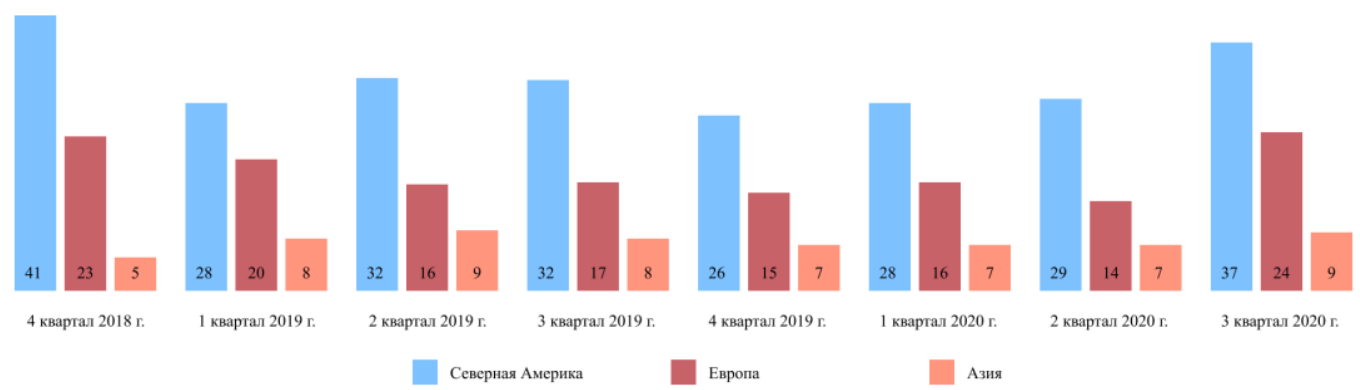

Puc. 3. Источник: https://www.cbinsights.com/research/report/venture-capital-q3-2020/ (дата обращения 17.01.2021).

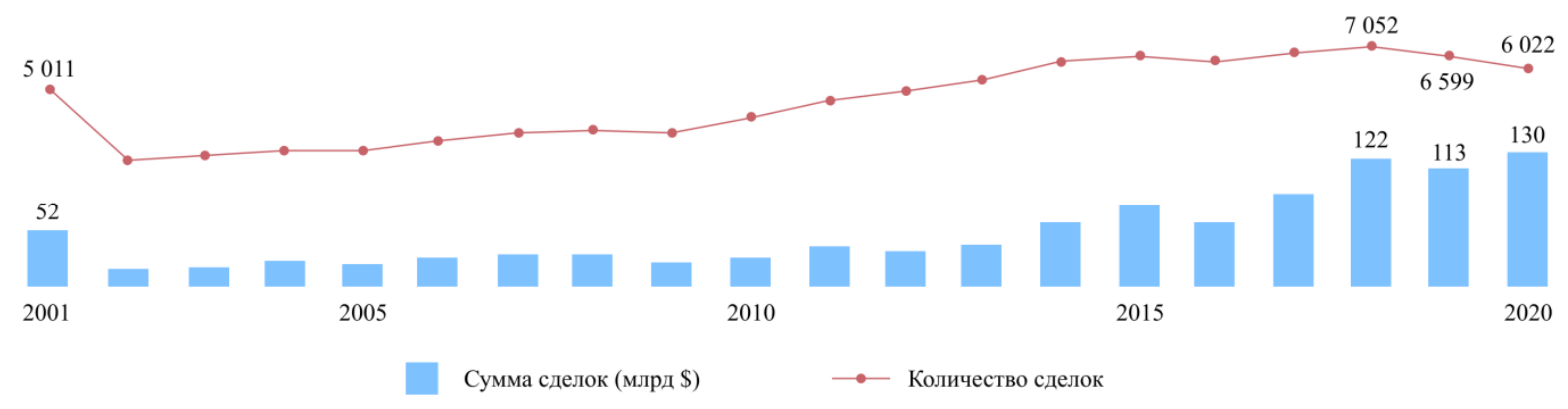

Puc. 4. Источник: https://www.cbinsights.com/research/report/venture-capital-q1-2021/ (дата обращения 17.01.2021). 
Американская экономика постиндустрий не сдает технологических позиций [15] благодаря конвергентным исторически сложившимся факторам, которые в том числе способствуют и устойчивому развитию штатов:

1. Состояние рискового капитала. Структура и объем венчурных средств на рынке ежегодно наполняется множеством супер и бизнесангелов, студий венчуринга, краудфандинговых платформ*, пенсионных фондов, страховых компаний, корпоративных инвесторов, РЕ и VC-фондов, частных некоммерческих организаций США, производящих вложения в венчурные проекты (Рис. 4). К 2018 г. в венчурной индустрии Соединенных Штатов одних действующих фондов насчитывалось свыше 1 тыс.

2. Бизнес-ментальность и восприятие риска. Важным элементом для функционирования инновационной инфраструктуры является ментальность ее участников. Предприниматели, воспитанные в этике американского социума, готовы в данном случае брать на себя коммерческие риски и даже превозносить собственные неудачи. Бывшая страна ВАСПов сумела предложить индивиду следующий императив поведения: «Я хотя бы попробовал».

3. Возможность «выхода» из проекта на начальных стадиях. Основные покупатели стартапов в США - транснациональные ИТ-гиганты Amazon, Google, Facebook, Apple, IBM, Microsoft. Они приобретают в среднем по 1-2 стартапа в неделю, подобные сделки, как правило, не афишируются, представляя собой покупку «посевных» инженерных команд и их продуктовых ин- новаций.

4. Локальные центтры сосредоточения определенного сегмента технологий по итатам. В целом, высокая инновационная активность в таких кластерах обусловлена концентрацией венчурных предприятий и отпочковывающихся компаний вокруг крупных университетов [16], подключенных к системе трансфера технологий. Выпускники и аспиранты позднее запускают там и свои стартапы, не оставляя надежды вырастить новый «единорог» с мировым признанием.

5. Права интеллектуальной собственности. Американские инвесторы всегда требуют запатентовать зарубежную разработку в США, и главная причина тому,- бенефиты венчурования на территории страны, где аккумулирован международный рисковый капитал, по объемам превосходящий японскийж**** и европейскийн********. Никто не будет инвестировать в посев, чья интеллектуальная собственность не защищена в Соединенных Штатах, а тем более тратить время и деньги на оценку проектных рисков. Созданный в стране механизм правовой охраны и использования результатов интеллек-

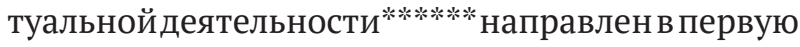
очередь на имплементирование национальной научно-технологической политики. Упомянутая бизнес-ментальность американцев не позволяет им вносить денежные средства в то, что не будет заявлять всему миру об их достижениях. Патентно-правовая база - это один из определяющих факторов институциональной инфраструктуры венчуринга (Рис. 5, 6).

\footnotetext{
* ТоркановскийЕ.П.Коллективные инвестиции в инновационной экономике: значение и перспективы // Экономика и экономические науки, 2017.- № 1 (65)._ URL: https://cyberleninka.ru/article/n/kollektivnyeinvestitsii-v-innovatsionnoy-ekonomike-znachenie-i-perspektivy

** Международные экономические отношения: реалии, вызовы и перспективы: монография / [Л.С. Ревенко, В. В. Перская, А. В. Холопов и др.]; под общ. ред. и с предисл. Л. С. Ревенко; Моск. гос. ин-т междунар. отношений (ун-т) МИД России, каф. междунар. экон. отношений и внешнеэкон. связей им. Н.Н. Ливенцева.- М.: МГИМО-Университет, 2019.- С. 453, [1].

*** Воинов А. И. Государственное регулирование инновационных процессов в Японии // Биржа интеллектуальной собственности, 2015.- № 2.- С. 31-35.

**** Torkanovskiy, E. (2016). Non-Equity Crowdfunding as National Phenomenon in Global Industry: Russia Case. In D. Brüntje \& O. Gajda (Eds.), Crowdfunding in Europe - State of the Art in Theory and Practice. Cham: Springer International Publishing._- URL: https://doi.org/10.1007/978-3-319-18017-5_8

****** Воинов А.И.Приоритеты инновационной политики стран ЕС // Страховое дело, 2017.- № 1.- С. 7.

****** Леонтьева В.Б.Стратегия США в сфере интеллектуальной собственности [Электронный ресурс].URL: https://cyberleninka.ru/article/n/strategiya-ssha-v-sfere-intellektualnoy-sobstvennosti (дата обращения 20.03.2021).
} 


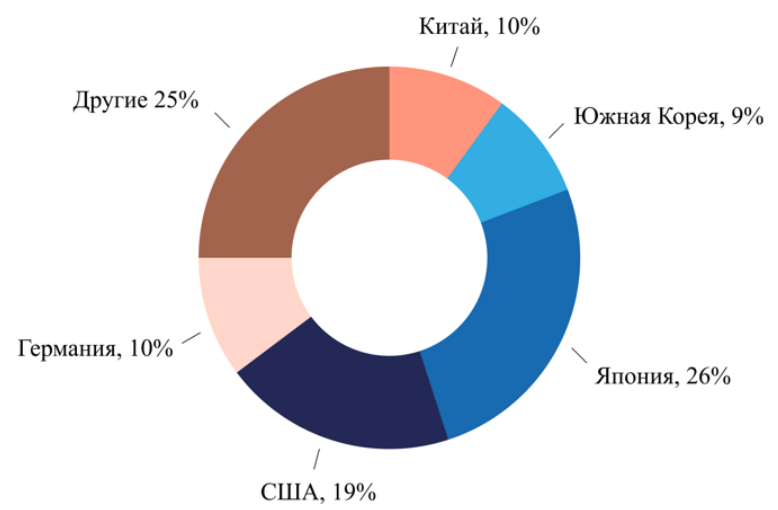

Pис. 5. Источник: https://www.weforum.org/reports/the-global-competitiveness-report-2020 (дата обращения 28.01.2021).

\section{Объем венчурного капитала по регионам мира в 2020 году, млрд \$}

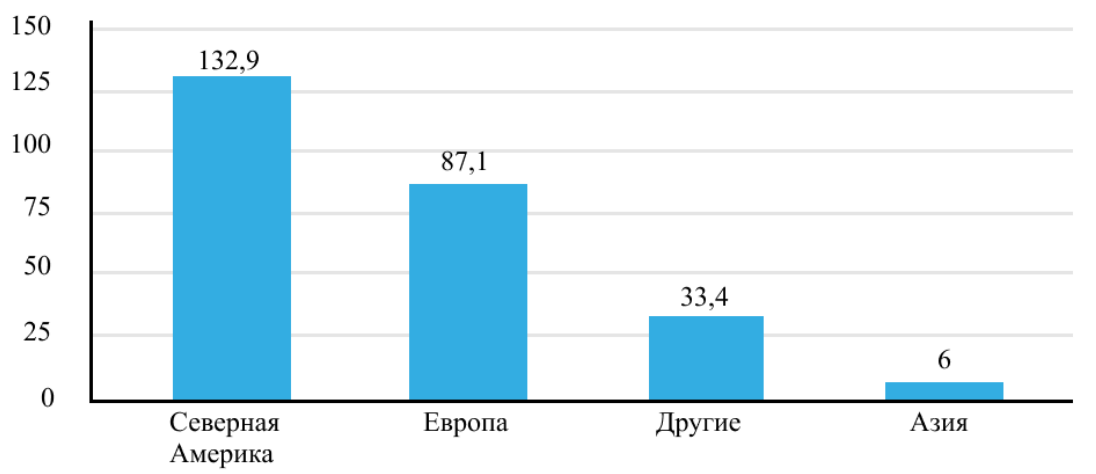

Puc. 6. Источник: https://www.statista.com/statistics/1095957/global-venture-capita-funding-value-byregion/ (дата обращения 15.02.2021).

\section{Основные критерии отбора проектов}

Предоставляя финансирование с крайне высокой степенью риска, даже искушенные многолетней практикой инвесторы не спешат вкладываться в стартап. Для минимизации имеющихся рисков инвесторы оценивают его по весьма широкому спектру критериев [17] [18].

\section{1. Транспарентность рынка}

Венчурный капиталист ожидает от владельца стартапа наличие будущих клиентов, а также полное понимание особенностей занимаемой ниши. Приемлемое количество потенциальных потребителей (пользователей) разрабатываемого продукта - в пределах 10-20 млн. человек.

\section{2. «Горячие» ниши - Hot Niche}

При отсутствии целевых и грантовых форм государственно-частно-академической под- держки инвесторы чаще фокусируются на «горячих» стартапах. К примеру, такой стартап вполне может реализовываться в сферах on-demand есоnomy (экономика по требованию) или sharing есоnomy (экономика совместного пользования).

\section{3. Звездная команда - Star team}

В команде стартапа сегодня востребованы «большие» умы, цитируемые в международных научных изданиях, желательно не только с техническим, но и с бизнес-образованием. Выполнение этого условия гарантирует, что все члены команды отчетливо понимают, для чего они работают в созданном коллективе.

- Full commitment - полная отдача по обязательствам

Венчурных капиталистов привлекают стартап-команды, которые готовы трудиться на 
общее дело с ненормированным графиком исполнителей.

\section{4. Финансовый прогноз}

- CAC и LTV

Оценка проектных цифр и показателей компании на перспективу: стоимости привлечения клиента (customer acquisition cost - CAC), доходности с привлеченного клиента за весь период сотрудничества с ним (customer lifetime value LTV).

\section{- Funding strategy}

Стартап должен иметь финансовый план, где будут подробнейшим образом расписаны расходы на ближайшие несколько лет.

\section{- Break-even point - Точка безубыточно-} сти

Инвесторы заинтересованы в достижении точки безубыточности (break-even), как можно раньше проходя «долину смерти» жизненного цикла.

\section{5. Показатели роста}

- Extraordinary virality - показатели быстрорастущей компании

Для венчурования компании огромное значение имеет и то обстоятельство, насколько стремительно развивается проект. Такие показатели дадут дополнительные гарантии по возврату денежных средств инвестору.

\section{6. Выручка с опережением}

Рисковый капиталист-посредник всегда предпочтет стартап, когда еще до стадий полу- чения существенного финансового вливания из проекта извлекается прибыль («ранний рост», «расширение»). В хорошо коммерциализируемом сегменте цифровых технологий некоторые посевные команды уже успешно реализуют подобные схемы.

\section{7. Своевременность предложения}

Это актуальность и высокая степень привлекательности проекта для инвесторов в текущей конъюнктуре рынка. Отдельного упоминания заслуживает предпандемическая ситуация 2019 г., вызвавшая впоследствии серьезные социально-экономические сбои в мировом хозяйстве. Несмотря на сложившиеся обстоятельства национальный рынок венчуров в 2020 г. показал положительную динамику* (Рис. 7). Так, лишь за первый квартал 2019 г. венчурные фонды мобилизовали около $\$ 21$ млрд., профинансировав 2298 сделок. Сумма привлеченных средств составляет половину от всего объема рискового капитала США за 2018 год, что само по себе является выдающимся результатом. Дефицита посевных инвестиций в период «COVID-19» не наблюдается, наоборот, идет активный рост их притока [19].

\section{8. Юридическая документация}

Качественное юридическое сопровождение процесса венчурования - еще один обязательный пункт дальнейшего продвижения по стадиям жизненного цикла. Стартаперам и финансистам следует пользоваться единым понятийным

* Итоги рынка венчурного капитала за 2020 год [Электронный ресурс].- URL: https://www.forbes.ru/karera-isvoy-biznes/417737-rynok-pobil-rekord-vseh-vremen-venchurnye-itogi-2020-goda (дата обращения 19.02.2021).

Сумма венчурных инвестиций в США по отраслям за 4 квартал 2020 года, млн \$

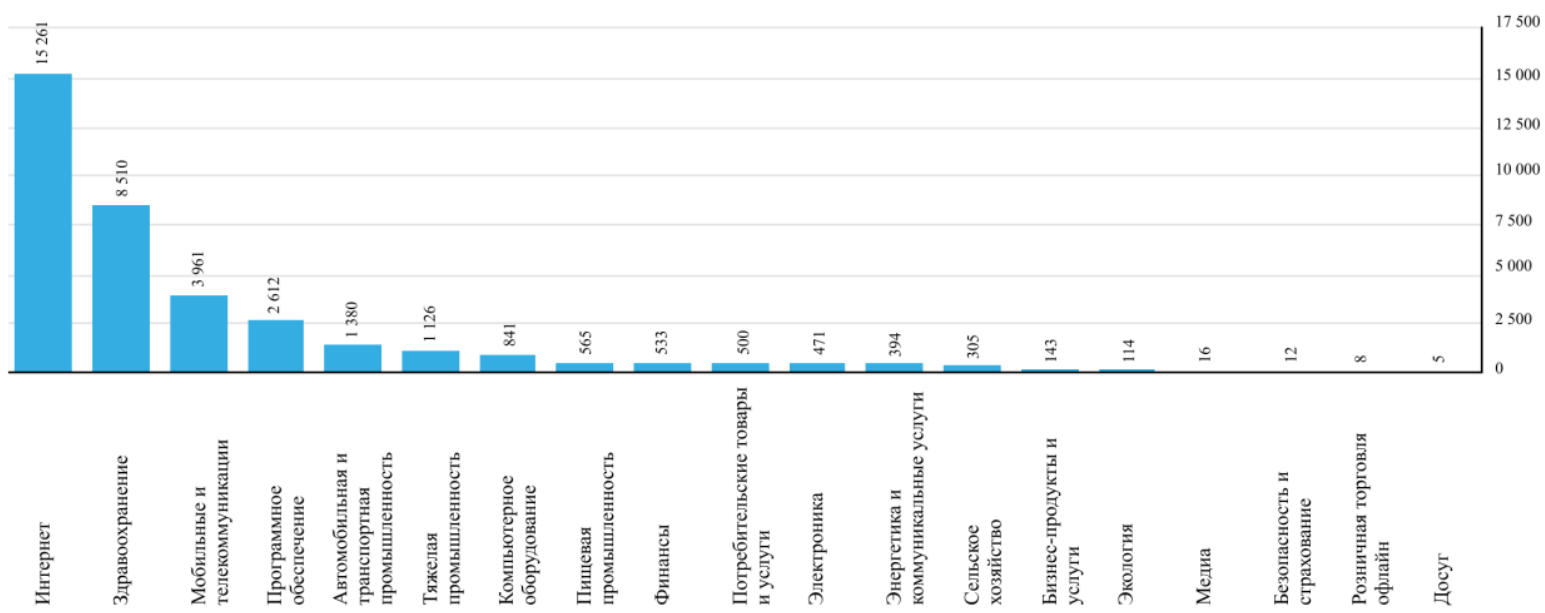

Puc. 7. Источник: https://www.statista.com/statistics/277506/venture-caputal-investment-in-the-unitedstates-by-sector/ (дата обращения 18.03.2021). 
аппаратом и общепринятой терминологией бизнес-среды инноваторов, а также выбирать более выгодные юрисдикции американских штатов.

9. Профессионализм гендиректора - Ве Pro CEO

- Отличная «подача» с историей - Great pitch with story

В креативном поведении особую роль играют субстантивные личные качества команды (soft skills) и, в частности, харизма ее основателя. Обогащенность знанием иностранных языков, социокультурных традиций дополненная навыками ведения переговоров, умением коммуницировать заметно сократит продолжительность периода поиска инвестиций.

- Функциональная демонстрация Functional demo

Приглашаемые на демо-день потенциальные инвесторы должны понять принцип действия улучшенного продукта, который предлагается стартапом. Здесь очень поощряется создание различных вариантов демоверсий, прототипов и т.д. Необходимо передать ощущения того, что инвестор смог с удовольствием воспользоваться набором потребительских свойств новшества.

\section{0. Локализация проекта - Be in the USA}

В случае проживания разработчиков технологического решения где-либо за пределами США, их отсутствие допускается лишь на стадии посевов. Ожидания венчурной индустрии направлены на нахождение зарубежных стартаперов на территории страны. Это определяет уровень реальной коммуникации между основателем и командой, качество контроля, легальность и соблюдение прочих условий.

\section{- 50-тимильная зона - $\mathbf{5 0}$ miles rule}

Негласное правило, о котором ставят в известность на месте во всех американских фондах: «Если ваш руководитель находится больше чем в 50 милях от нашего руководителя - нам неинтересно с вами разговаривать». Простота транспортной доступности инвестора и основателя друг к другу сегодня ценится в особенности.

\section{Библиографический список}

1. Рыбин М.В., Воинов А. И. Теоретические аспекты и развитие методов управления инновациями // Экономические науки, 2020.- № 4.- С. 37-43.

2. Плотников Д.А. Венчурный бизнес: опыт США // Инновационная деятельность, 2009. - № 2 (7). - С. 6268. - URL: https://elibrary.ru/item.asp?id=12858260 (дата обращения 18.12.2019).

3. Воинов А.И. Особенности научно-технологической политики США // Финансовый бизнес, 2015. - № 3.- С. 57-61.

4. Варнавский В.Г., Зельднер А.Г., Мочальников В.Н., Сильвестров С.Н. Основы государственно-частного партнерства (теория, методология, практика).-М.: Анкил, 2015.

5. Современные международные экономические отношения в эпоху постбиполярности: монография / Т. М.Исаченко, Л.С. Ревенко, И.Н.Платонова [и др.]; под общей редакцией Т. М.Исаченко.- М.: МГИМО-Университет, 2020.- С. 536-545.

6. Воинов А. И. Национальная научно-технологическая политика Китая // Биржа интеллектуальной собственности, 2015. - № 3.- С. 40, 41.

7. Торкановский Е.П. Коллективные инвестиции в инновационной экономике: значение и перспективы // Экономика и экономические науки, 2017. - № 1 (65)._- URL: https://cyberleninka.ru/article/n/kollektivnyeinvestitsii-v-innovatsionnoy-ekonomike-znachenie-i-perspektivy

8. Международные экономические отношения: реалии, вызовы и перспективы: монография / [Л. С. Ревенко, В.В.Перская, А.В.Холопов и др.]; под общ. ред. и с предисл. Л. С. Ревенко; Моск. гос. ин-т междунар. отношений (ун-т) МИД России, каф. междунар. экон. отношений и внешнеэкон. связей им. Н.Н.Ливенцева.М.: МГИМО-Университет, 2019.- С. 453, [1].

9. Воинов А.И. Государственное регулирование инновационных процессов в Японии // Биржа интеллектуальной собственности, 2015.- № 2.- С. 31-35.

10. Torkanovskiy, E. (2016). Non-Equity Crowdfunding as National Phenomenon in Global Industry: Russia Case. In D. Brüntje \& O. Gajda (Eds.), Crowdfunding in Europe - State of the Art in Theory and Practice. Cham: Springer International Publishing. - URL: https://doi.org/10.1007/978-3-319-18017-5_8

11. Воинов А. И. Приоритеты инновационной политики стран ЕС // Страховое дело, 2017. - № 1.- С. 7 .

12. Леонтьева В.Б. Стратегия США в сфере интеллектуальной собственности [Электронный pecypc].- URL: https://cyberleninka.ru/article/n/strategiya-ssha-v-sfere-intellektualnoy-sobstvennosti (дата обращения 20.03.2021). 
13. Useful Stats [Электронный ресурс].- URL: http://ssti.org/blog/useful-stats-share-us-venture-capital-activityand-capita-investment-state-2010-2016 (дата обращения 15.04.2020).

14. National Venture Capital Association Yearbook 2016 [Электронный ресурс].- URL: https://ru.scribd.com/ doc/303181082/NVCA-Yearbook-2016 (дата обращения 29.03.2020).

15. Индекс конкурентоспособности США [Электронный ресурc].- URL: https://gtcistudy.com/the-gtciindex/\#gtci-country-view (дата обращения 19.03.2021).

16. Модели венчурных инвестиций в России и США как основной элемент становления инновационных предприятий [Электронный ресурс]. - URL: https://www.researchgate.net/publication/338256745_Venture_Capital_ Investments_Models_in_Russia_and_the_USA_as_Key_Factor_for_Development_of_Innovative_Enterprises/fulltex t/5e0b7043299bf10bc38557d6/Venture-Capital-Investments-Models-in-Russia-and-the-USA-as-Key-Factor-forDevelopment-of-Innovative-Enterprises.pdf (дата обращения 14.04.2020).

17. Критерии оценки выгоды венчурных вложений в проект на американском рынке 2019 [Электронный реcypc]. - URL: https://ru.wiki.rademade.com/fundraising-usa (дата обращения 20.11.2019).

18. Стартап на экспорт: 8 различий венчурного мира США и России 2020 [Электронный ресурс]. - URL: https:// www.forbes.ru/tehnologii/337017-startap-na-eksport-8-razlichiy-venchurnogo-mira-ssha-i-rossii (дата обращения 5.02.2020).

19. Рынок венчурных инвестиций США 2020 [Электронный ресурc].- URL: http://www.tadviser.ru/index.php/ Статья: Венчурное_инвестирование (дата обращения 20.02.2020).

20. Итоги рынка венчурного капитала за 2020 год [Электронный pecypc].- URL: https://www.forbes.ru/ karera-i-svoy-biznes/417737-rynok-pobil-rekord-vseh-vremen-venchurnye-itogi-2020-goda (дата обращения 19.02.2021). 